See discussions, stats, and author profiles for this publication at: https://www.researchgate.net/publication/324444838

\title{
Development of an Efficient Dual-Action GST-Inhibiting Anticancer Platinum(IV) Prodrug
}

Article in ChemMedChem · February 2018

Dol: $10.1002 / \mathrm{cmdc} .201800105$

\section{CITATIONS}

13

7 authors, including:

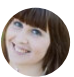

Masha Babak

City University of Hong Kong

32 PUBLICATIONS 500 CITATIONS

SEE PROFILE

Wee Han Ang

National University of Singapore

110 PUBLICATIONS 5,148 CITATIONS

SEE PROFILE

Some of the authors of this publication are also working on these related projects:

Project Pt anticancer drugs View project

Project

Modified Indolylpyrimidylpiperazines View project
39 PUBLICATIONS 693 CITATIONS

SEE PROFILE 


\title{
Development of an Efficient Dual-Action GST-Inhibiting Anticancer Platinum(IV) Prodrug
}

\author{
Keefe Guang Zhi Lee, ${ }^{[a]}$ Maria V. Babak, ${ }^{[a]}$ Andrea Weiss, ${ }^{[b]}$ Paul J. Dyson, ${ }^{[c]}$ \\ Patrycja Nowak-Sliwinska, ${ }^{[b]}$ Diego Montagner, ${ }^{*[d]}$ and Wee Han Ang ${ }^{*[a]}$
}

\begin{abstract}
The cytotoxicity of cisplatin (cDDP) is enhanced when co-administered with ethacrynic acid (EA), a glutathione S-transferase (GST) inhibitor. A Pt $\mathrm{It}^{\mathrm{IV}}$-EA conjugate containing a CDDP core and two axial ethacrynate ligands (compound 1) was shown to be an excellent inhibitor of GST, but did not readily release a Pt" species to exert a synergistic cytotoxic effect. In this study, a redesigned $\mathrm{Pt}^{\mathrm{IV}}$ construct composed of a cDDP core with one axial ethacrynate ligand and one axial hydroxido ligand (compound 2) was prepared and shown to overcome
\end{abstract}

the limitations of compound $\mathbf{1}$. The EA ligand in $\mathbf{2}$ is readily released in vitro together with a cytotoxic Pt" species derived from cisplatin, working together to inhibit cell proliferation in CDDP-resistant human ovarian cancer cells. The in vitro activity translates well in vivo with 2 , showing effective $(\sim 80 \%)$ inhibition of tumor growth in a human ovarian carcinoma A2780 tumor model, while showing considerably lower toxicity than cisplatin, thus validating the new design strategy.

\section{Introduction}

Cisplatin (CDDP) constitutes one of the most common chemotherapy options for treating a wide variety of cancers today. ${ }^{[1]}$ However, their continued development is hampered, at least in part, by platinum-associated drug resistance. For example, some types of cancer, colorectal cancer, possess intrinsic resistance to cDDP while others, for example, ovarian cancer, develop acquired resistance after successive rounds of chemotherapy. ${ }^{[2]}$ The proliferation of these adapted tumors leads to subsequent generations of cancer cells being increasingly able to cope with the same dose of CDDP through decreased uptake, increased efflux, or through improved DNA repair mechanisms. ${ }^{[3]}$ Over time, the effectiveness of the platinum-based chemotherapy regimen diminishes, invalidating it as a viable treatment option, and decreasing the patient's chances of survival. It would be advantageous, therefore, to devise new drug treatment options that are able to concomitantly overcome resistance mechanisms and significantly enhance efficacy.

[a] K. G. Z. Lee, Dr. M. V. Babak, Prof. W. H. Ang

Department of Chemistry, National University of Singapore, 3 Science Drive

3, Singapore 117543 (Singapore)

E-mail:ang.weehan@nus.edu.sg

[b] Dr. A. Weiss, Prof. P. Nowak-Sliwinska

School of Pharmaceutical Science, University of Geneva (UNIGE), 1211 Geneva (Switzerland)

E-mail:patrycja.nowak-sliwinska@unige.ch

[c] Prof. P. J. Dyson

Institut des Sciences et Ingénierie Chimiques, École Polytechnique Fédérale de Lausanne (EPFL), Lausanne (Switzerland)

[d] Dr. D. Montagner

Department of Chemistry, Maynooth University, Maynooth (Ireland) E-mail:Diego.Montagner@mu.ie

$\square$ Supporting information and the ORCID identification number(s) for the

(iD) author(s) of this article can be found under: https://doi.org/10.1002/cmdc.201800105.
Combination therapy has become an increasingly useful strategy for cancer treatment. The basic premise is that a combination of appropriately chosen drugs, usually with complementary mechanisms, would have effects that are synergistic, producing an overall result that is greater than the sum of the individual drugs' effects. For example, the combination of paclitaxel and carboplatin is the standard-of-care against ovarian cancer. Paclitaxel inhibits DNA repair in the cancer cells following carboplatin-induced DNA damage, thereby promoting cell death of the malignant ovarian cancer cells. ${ }^{[4]}$ Drug synergy may also be achieved when one drug boosts the effectiveness of the other by increasing the residence time of the latter in vivo, through blocking drug excretion by transport pumps or rendering detoxification mechanisms inactive. For instance, flavonoids were found to be able to affect the accumulation of doxorubicin in HCT-15 colon cancer cells through binding with P-glycoprotein, an efflux pump for cytotoxic drugs. ${ }^{[5]}$ One notable detoxification enzyme implicated in platinum-based drug resistance is glutathione S-transferase (GST), which catalyzes the conjugation of glutathione (GSH) to xenobiotics such as cisplatin, and facilitates their excretion via the mercapturic acid pathway. ${ }^{[6]}$ In fact, it has been shown that the role of GST is so significant that its activation confers cisplatin resistance upon breast cancer cells. ${ }^{[7]}$

The GST inhibitor ethacrynic acid (EA), is known to sensitize cancer cells to platinum-based cell death mechanisms and, more generally, to boost the sensitivity of resistant cancer cells toward alkylating agents. ${ }^{[8]}$ In addition, the strategy of tethering other molecules, including anticancer drugs, to a $\mathrm{Pt}^{\mathrm{IV}}$ scaffold is widely used in the pursuit of increasingly effective cancer therapies. ${ }^{[9]}$ Based on these data, we designed the CDDP-EA conjugate 1, a Pt ${ }^{\mathrm{IV}}$ prodrug that should release CDDP and two EA moieties in reducing intracellular conditions, with 
the constituent parts acting in concert to enhance the activity of cDDP (Figure 1). ${ }^{[10]}$ To our knowledge, 1 was the first such dual-action $\mathrm{Pt}^{\mathrm{IV}}$ complex which combined a bioactive axial ligand with a cytotoxic Pt"-based core template. Since the pub-<smiles>C=C(CC)C(=O)c1ccc(OCC(=O)OP(N)(N)(Cl)OC(=O)COc2ccc(C(=O)C(=C)CC)c(Cl)c2Cl)c(Cl)c1Cl</smiles><smiles>C=C(CC)C(=O)c1ccc(OCC(=O)O)c(Cl)c1Cl</smiles>

Figure 1. Structures of CDDP, EA, the previously reported $\mathrm{Pt}^{\mathrm{tV}}$ conjugate $\mathbf{1}$, and new conjugate 2 described in this study.

lication of its synthesis and properties in 2005, a multitude of other $\mathrm{Pt}^{\mathrm{IV}}$ complexes with multiple modes of action have been reported, including examples of complexes with enhanced cytotoxicity, immuno-chemotherapeutic properties, targeting capabilities, selective activation for photodynamic therapy, or complexes linked with other reporters for theranostics. ${ }^{[1]]}$

Despite our intention during its design, 1 functioned as a highly potent, but suicidal GST inhibitor in vitro with the $\mathrm{Pt}$ moiety being sandwiched at the GST dimer interface by bridging Cys101 residues. ${ }^{[12]}$ It seems likely that CDDP could not be efficiently released from 1 due to its low reduction rate. Furthermore, 1 exhibited a strong affinity to GST because the two EA moieties were able to directly interact with both of the substrate binding pockets in the GST dimer. Hence, we sought to overcome the limitations of 1 by decreasing the reduction potentials of the $\mathrm{Pt}^{\mathrm{IV}}$ construct, as well as by lowering the GST binding affinity through structural design ${ }^{[13]}$ Herein, we report a new $\mathrm{Pt}^{\mathrm{IV}}$ prodrug scaffold, 2, containing a single axial EA ligand, and evaluated its properties against 1, most notably its GST inhibition potency, cytotoxicity, and reduction kinetics. Due to the superior properties of $\mathbf{2}$, an in vivo study was also performed that demonstrates the high clinical potential of this new rationally designed $\mathrm{Pt}^{\mathrm{IV}}$ drug.

\section{Results and Discussion}

\section{Chemistry}

The $\mathrm{Pt}^{\mathrm{IV}}$ complex 1 was synthesized using a modified literature procedure. ${ }^{[10]}$ Oxalyl chloride was first used to transform EA into the activated acid chloride, which was then coupled to oxoplatin. Both axial $\mathrm{OH}$ ligands reacted directly with EA acyl chloride in an esterification reaction to form 1 in moderate yield (Scheme 1). This methodology could not be applied to synthesize the monofunctionalized variant 2, due to the high electrophilicity and reactivity of EA acyl chloride even with stoichiometric control of the reagents. To circumvent this problem, EA was instead activated by coupling the carboxyl group to $\mathrm{N}$-hydroxysuccinimide (NHS). Being a weaker electrophile than EA acyl chloride, the NHS ester derivative reacted with oxoplatin at a slower rate, enabling the monosubstituted $\mathrm{Pt}^{\mathrm{IV}}$ complex 2, to be obtained as the major product when a slight excess of oxoplatin was used. Preparative reverse-phase HPLC (RP-HPLC) was used to further purify the products to $>99 \%$ to ensure sufficient purity for biological testing.

\section{Biological assays \\ Inhibition of GST activity}

The GST inhibitory activity of $\mathbf{2}$ was determined along with 1, CDDP, and free EA using the established 1-chloro-2,4-dinitrobenzene (CDNB) photometric assay protocol adapted from Habig et al., using commercial GST enzymes purified from<smiles>C=C(CC)C(=O)c1ccc(OCC(=O)ON2C(=O)CCC2=O)c(Cl)c1C(=O)CCCCCCC(=O)c1ccc(OCC(=O)OP(N)(N)(Cl)Cl)c(Cl)c1Cl</smiles>

Scheme 1. Synthesis of $\mathrm{Pt}^{\mathrm{IV}}-\mathrm{EA}$ complexes $\mathbf{1}$ and $\mathbf{2}$. 
human placenta as a realistic model of human GST in vivo. ${ }^{[14]}$ Consistent with the previous study, 1 was found to be the most potent GST inhibitor, two orders of magnitude more potent than 2 and EA. Removal of an EA moiety significantly diminishes the GST inhibitory activity of 2 relative to 1 based on $\mathrm{IC}_{50}$ and calculated $K_{\mathrm{i}}$ data (Table 1 ). In an earlier solid-state

\begin{tabular}{|cccc|}
\hline \multicolumn{4}{|l|}{ Table 1. Enzyme assays of GST inhibitors. } \\
Compound & Calcd $K_{\mathrm{i}}[\mathrm{nM}]$ & $\mathrm{IC}_{50}[\mathrm{~nm}]^{[\mathrm{a}]}$ & $K_{\mathrm{M}}[\mu \mathrm{M}]$ \\
\hline 1 & $47 \pm 6.6$ & $38.7 \pm 4.2$ & $0.69 \pm 0.02$ \\
2 & $899 \pm 117$ & $2800 \pm 600$ & $0.68 \pm 0.04$ \\
EA & $2260 \pm 460$ & $7920 \pm 1070$ & $0.76 \pm 0.04$ \\
CDDP & N.D. ${ }^{[b]}$ & $19900 \pm 2900$ & N.D. \\
\hline
\end{tabular}

[a] Values are the mean $\pm S D$ from at least three independent experiments. [b] $K_{\mathrm{i}}$ was not calculated for cisplatin, as its mode of inhibition was not determined.

structural analysis of GSTP1-1 single crystals soaked with 1, we observed that 1 was ideally oriented to directly interact with each of the EA-binding sites on the dimeric GST enzyme (one binding site per GST monomer). Furthermore, the Cys101 residues at the dimer interface could opportunistically reduce and bind Pt covalently, giving rise to the strong multimodal interaction between GSTP1-1 and 1. ${ }^{[12]}$ The removal of one EA moiety would prevent these synergistic interactions, enabling $\mathbf{2}$ to function as a conventional inhibitor in a similar manner to EA, validating our design strategy. Based on the Lineweaver-Burk plots, the modes of inhibition for all compounds tested were found to be noncompetitive with respect to CDNB (see Supporting Information (SI)). ${ }^{[15]}$ This differs from earlier reports due to different GST enzymes used as well as incubation times. ${ }^{[12,16]}$ Upon prolonged exposure to GSH, EA can form an EA-GSH covalent adduct conjugate that exhibits different modes of GST inhibition, noncompetitive with respect to CDNB, as compared with unconjugated EA. ${ }^{[17]}$

\section{Reduction rates of $\mathrm{Pt}^{\prime V}$ prodrug complexes}

To examine the possibility of $\mathbf{1}$ and $\mathbf{2}$ being viable prodrugs which could be easily reduced in vivo, a reduction kinetics study was carried using ascorbate as the biological reductant.
We earlier showed that under reducing conditions, $\mathrm{Pt}^{\mathrm{IV}}$ complexes with both axial ligand positions occupied by carboxylate ligands were significantly more resistant to reduction than congeners with a carboxylate and a hydroxide at the axial ligand positions. ${ }^{[13]}$ These mono-carboxylate $\mathrm{Pt}^{\mathrm{IV}}$ complexes were prone to reduction because the hydroxido ligand facilitated $\mathrm{H}$-bonding to the ascorbate reductant, thus accelerating the reduction rates. While this study was intended to mimic biological conditions, the poor solubility of $\mathbf{1}$ in aqueous media necessitated the preparation of a DMSO stock solution, and addition of THF co-solvent to prevent 1 from precipitating out of the reaction mixture. By comparison, $\mathbf{2}$ was more soluble in phosphate buffer at the required concentrations due to the substitution of the hydrophobic ethacrynate ligand with the hydrophilic hydroxide moiety. Initially, a biologically relevant ascorbate concentration of $3 \mathrm{~mm}$ was used, and the concentration of 1 was lowered to the point where ascorbate was in an approximate 300-fold excess. This was done to achieve pseudo-first-order kinetics, where any changes in the reaction rate could be assumed to be due only to changes in the $\mathrm{Pt}^{\text {IV }}$ complex concentration. Aqueous stabilities of $\mathbf{1}$ and $\mathbf{2}$ were ascertained over a period of three days, to ensure that the disappearance of the starting material would be only due to the reduction reaction, and not due to unwanted side-reactions. In the absence of reductants, $\mathbf{1}$ and $\mathbf{2}$ were found to be stable in aqueous solutions.

Reduction rates were determined using HPLC to quantify residual levels of $\mathbf{1}$ and $\mathbf{2}$ after addition of ascorbate (Table 2). While the reduction of 1 under the aforementioned conditions ( $3 \mathrm{~mm} \mathrm{Asc}$ ) could be readily assessed by monitoring the decrease of peak area, the peak representative of $\mathbf{2}$ could not be observed even at the point of the first HPLC injection, despite a more concentrated stock solution being used. We concluded that 2 was much more rapidly reduced under the same conditions used for 1, validating our initial hypothesis. Indeed, the ascorbate concentration had to be lowered by a factor of 200 before kinetics data were able to be obtained for the reduction of 2 . The dramatic difference in the reduction rates, via a simple ethacrynate ligand substitution, showed that $\mathbf{2}$ was much more susceptible to reduction than $\mathbf{1}$, and has the potential to be intracellularly reduced before interacting with its biological targets.

$$
\begin{aligned}
& \text { Table 2. Reduction kinetics of } \mathrm{Pt}^{\mathrm{tV}} \text { complexes. }
\end{aligned}
$$

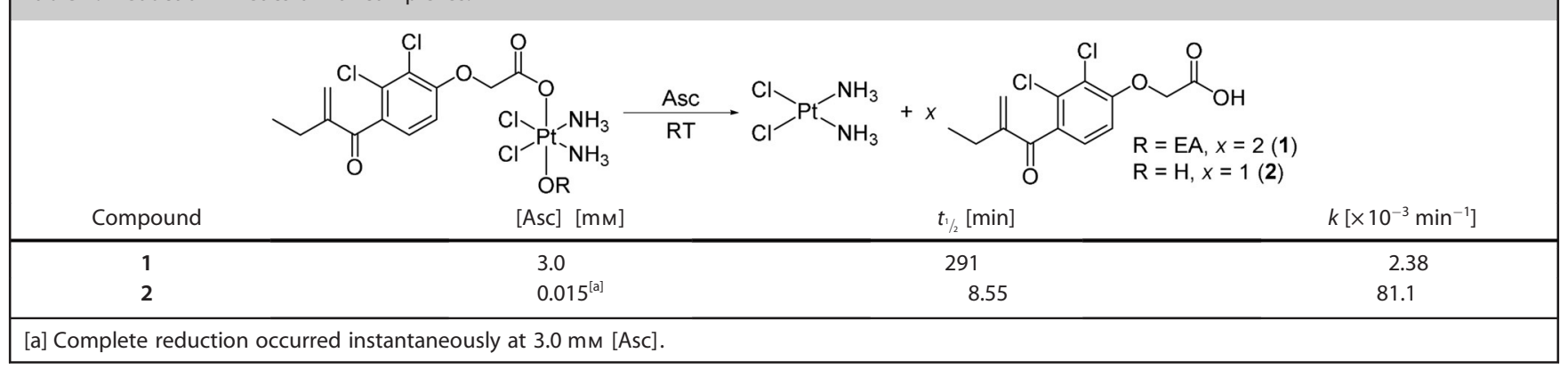




\section{In vitro studies}

The ability of $\mathbf{2}$ to inhibit cancer cell proliferation was evaluated against the A2780 ovarian cancer cell line and its CDDP-resistant variant, $A 2780 / c i s R$, using the MTT assay with 1, CDDP, and EA as controls (Table 3). Remarkably, $\mathbf{2}$ was the most

\begin{tabular}{|c|c|c|c|}
\hline \multirow[t]{2}{*}{ Compound } & \multicolumn{2}{|c|}{$\mathrm{IC}_{50}[\mu \mathrm{M}]^{[\mathrm{a}]}$} & \multirow{2}{*}{$\begin{array}{c}\text { Resistance } \\
\text { factor }\end{array}$} \\
\hline & A2780 & A2780/cisR & \\
\hline 1 & $0.14 \pm 0.03$ & $0.52 \pm 0.12$ & 3.7 \\
\hline 2 & $0.07 \pm 0.02$ & $0.50 \pm 0.13$ & 7.1 \\
\hline EA & $30.00 \pm 5$ & $42.00 \pm 15$ & 1.4 \\
\hline cDDP & $0.59 \pm 0.08$ & $4.11 \pm 0.68$ & 7.0 \\
\hline \multicolumn{4}{|c|}{$\begin{array}{l}\text { [a] Values are the mean } \pm S D \text { from at least three independent experi- } \\
\text { ments. }\end{array}$} \\
\hline
\end{tabular}

potent compound against $A 2780$ and $A 2780 /$ cisR with $I C_{50}$ values in the same order of magnitude as $\mathbf{1}$. Both 1 and 2 exerted good cytotoxicities against the tested cell lines with $I C_{50}$ values lower than cDDP. Notably, even if apparently they were not able to overcome cDDP resistance in A2780/cisR (resistance factors of 3.7, 7.1 and 7.0 for 1, 2 and cisplatin, respectively), the activity of $\mathbf{2}$ is still eight times higher than that of cisplatin ( $\mathrm{IC}_{50} 0.50 \mu \mathrm{M}$ for 2 versus $4.11 \mu \mathrm{M}$ for cisplatin). They were also more cytotoxic than organometallic complexes based on Ru" and Os" centers modified with EA. ${ }^{[18]}$ This enhancement in cytotoxicity could arise from separate factors. The ethacrynate ligand increases the lipophilicity of the complexes, which would increase cellular uptake and accumulation relative to CDDP. Based on the data collected, it is unlikely that increased cellular accumulation is the dominant factor, as $\mathbf{1}$ is more lipophilic than $\mathbf{2}$ and therefore should be significantly more cytotoxic than $\mathbf{2}$, whereas the opposite was observed experimentally.

The ethacrynate moiety potentiates the antiproliferative activity of the $\mathrm{Pt}^{\mathrm{IV}}$ complexes by inhibiting GST detoxification pathways as designed. To confirm this hypothesis, cellular GST activities were determined after exposure to 1 and 2. Briefly, A2780 cells were exposed separately to 1, 2, EA or CDDP for $90 \mathrm{~min}$. Thereafter, the cells were harvested, lysed via freeze and thaw, and their intracellular GST activities determined using the afore-mentioned CDNB-GSH assay (Table 4). The data were normalized to EA equivalents-EA itself and 2 both contained one EA equivalent per molecule, while 1 contained two EA equivalents. Therefore, half the amount of 1 was used compared with 2 and EA. Based on the obtained results, residual GST levels after treatment with $\mathbf{1}$ and $\mathbf{2}$ were shown to be dose-dependent, and independent of antiproliferative activity. Intracellular GST activities in cells treated by 2 at $60 \mu \mathrm{m}$ were significantly inhibited, indicating that 2 could directly interfere with its intended biological target. Notably, despite using half the dose, $\mathbf{1}$ inhibited intracellular GST activity more effectively than $\mathbf{2}$ or EA, reaffirming earlier reports that it behaves as an

\begin{tabular}{|c|c|c|c|c|}
\hline Compound & {$[$ Low] $[\mu \mathrm{M}]$} & Res. act. [\%] ${ }^{[a]}$ & {$[\mathrm{High}][\mu \mathrm{M}]$} & Res. act. [\%] ${ }^{[a]}$ \\
\hline 1 & 5 & $54.9 \pm 17.6$ & 30 & $18.3 \pm 2.2$ \\
\hline 2 & 10 & $81.3 \pm 7.3$ & 60 & $45.3 \pm 2.6$ \\
\hline EA & 10 & $90.7 \pm 14.7$ & 60 & $80.5 \pm 18.2$ \\
\hline CDDP & 10 & $84.2 \pm 14.2$ & 60 & $72.2 \pm 14.4$ \\
\hline
\end{tabular}

[a] Values are the mean $\pm S D$ from at least three independent experiments.

efficient GST inhibitor. In comparison, EA was expected to be poorly active due to its carboxylic acid moiety, which would hinder its ability to traverse the cellular membrane. The GST inhibition property of cisplatin is similar to $\mathbf{2}$ at lower dose but is much lower at higher concentration and does not seem to be dose dependent. The lower dose used in this essay $(10 \mu \mathrm{M})$ is ten times higher than the $\mathrm{IC}_{50}$ concentration in A2780 cells but the values refer to 90 mins incubation time with respect to 72 hours for the MTT test. Taken together, the data suggest 2 could function as a $\mathrm{Pt}^{\mathrm{IV}}$ prodrug capable of inhibiting GST at a cellular level.

\section{In vivo study}

Based on the promising properties of $\mathbf{2}$ presented above, in vivo studies were conducted to benchmark the activity of 2 relative to CDDP. The chorioallantoic membrane of the chicken embryo implanted with A2780 ovarian tumors was used (see $\mathrm{SI}){ }^{[19]}$ The embryos were inoculated with tumor cells and treatment with various doses of $\mathbf{2}$ or CDDP was initiated after the appearance of vascularized tumors. Treatment was administered intravenously on two consecutive days, once daily. Tumor size and toxicity was monitored daily over a period of eight days. Compound $\mathbf{2}$ inhibited tumor growth in a dose-dependent manner. On the last day of the experiment, tumors in the control group reached an average volume of $309 \mathrm{~mm}^{3}$ (represented as $100 \%$ value of tumor volume in Figure $2 \mathrm{a}$ ). The growth of tumors treated with 2 at a dose of $10 \mu \mathrm{g} /$ embryo/day (corresponding to $16 \mathrm{nmol}$ ) was significantly inhibited by $77 \%$ (two-way ANOVA with post-hoc Dunnett's multiple comparisons test versus the DMSO-treated control, ${ }^{* *}$ indicates $p$-value $<0.01$ ). This study showed that $\mathbf{2}$ is able to effectively inhibit tumor growth in vivo with the ability to retard tumor growth is similar extension to that of CDDP at an equivalent dose (Figure 2 b); however, CDDP is much more toxic, as it resulted in more extensive embryo death at equivalent dose levels (Figure $2 b-c$ ). Therefore, it is possible that $\mathbf{2}$ might be as potent as CDDP, while having an improved safety profile.

\section{Conclusions}

A monofunctionalized $\mathrm{Pt}^{\mathrm{IV}}$ complex, 2, comprising a GST inhibitor conjugated to a Pt-based core, was prepared with the goal of accessing a Pt prodrug motif that could dissociate readily in an intracellular environment to yield a cytotoxic Pt" derivative and a GST inhibitor. The novel complex was found to be an effective GST inhibitor operating via a noncompetitive 


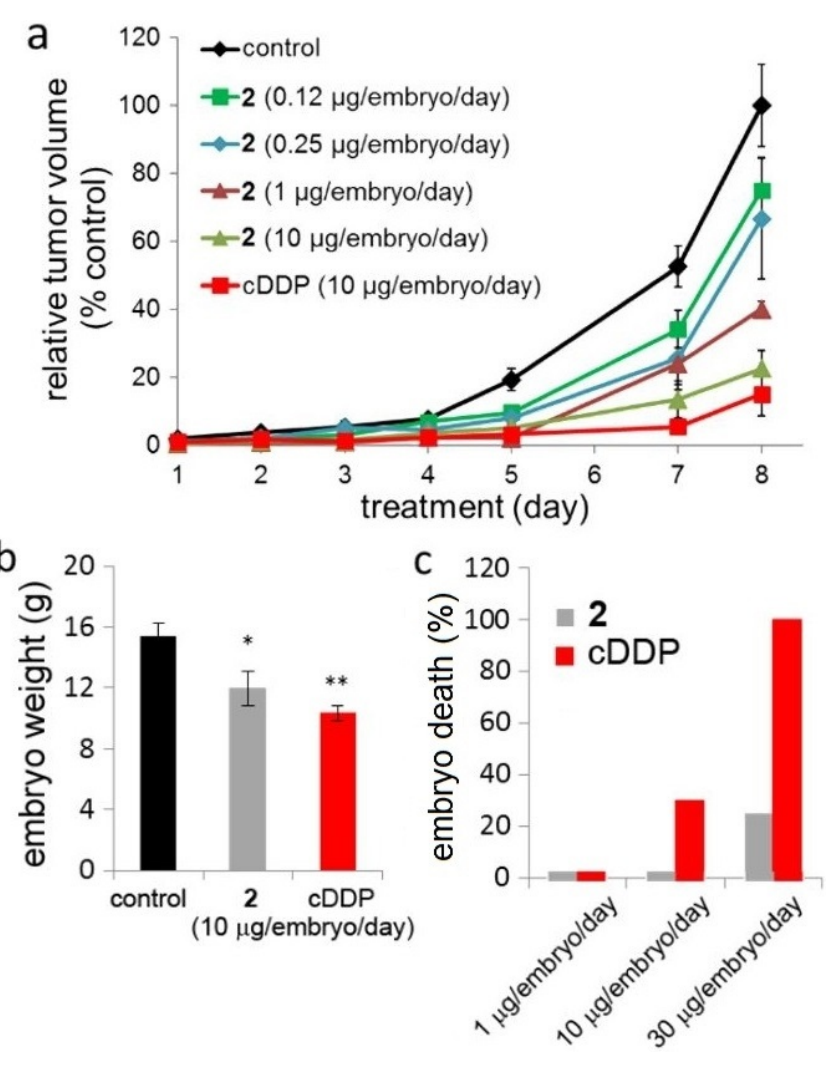

Figure 2. In vivo activity of $\mathbf{2}$ and CDDP in human ovarian carcinoma (A2780) in the CAM model. a) Tumor growth curves represent the following conditions: control (0.1\% DMSO), 2 (0.12-10 $\mu \mathrm{g} / \mathrm{embryo} /$ day) and cDDP $(10 \mu \mathrm{g} /$ embryo/day) as a positive control. b) Ex ovo embryo weight at the last (8th) experimental day upon tumor resection. (c) Dose-dependent embryo death rate on day 8 . Significance is indicated versus the DMSO-treated control; ${ }^{*} p<0.05,{ }^{* *} p<0.01$ (two-way ANOVA with post-hoc Dunnett's multiple comparisons test). Error bars represent standard error of the mean.

mechanism. The increased susceptibility of 2 to reduction relative to 1 was introduced by design using an asymmetric Pt $\mathrm{Pt}^{\mathrm{IV}}$ scaffold containing a hydroxido axial ligand to enhance $\mathrm{H}$ bonding interactions with potential biological reductants. Despite containing one EA moiety compared with two in compound 1, compound 2 remained a potent antiproliferative agent against CDDP-sensitive and CDDP-resistant cancer cells. Importantly, $\mathbf{2}$ was able to decrease tumor growth in vivo in a chicken embryo with significantly decreased toxicities relative to cisplatin, as evidenced by increased embryo survivals. Consequently, monofunctional $\mathrm{Pt}^{\mathrm{IV}}$ complexes that are more easily activated by reduction in vitro and in vivo could become an important class of rapidly activating $\mathrm{Pt}^{\mathrm{IV}}$ prodrugs with dual modes of actions.

\section{Experimental Section}

Materials: All reagents were purchased from commercial sources and used without further purification. Solvents were used as received, except for THF, which was dried using an MBraun SPS-800 solvent purification system. Ethacrynic acid (EA) was purchased from Abcam Singapore and GST (from human placenta, 25125 units $\mathrm{mg}^{-1}$ protein) was purchased from Sigma-Aldrich. Cispla- tin (CDDP), oxoplatin [cis-,cis-,trans-diamminedichlorodihidroxo platinum(IV)], and $\mathbf{1}$ were synthesized according to literature methods. ${ }^{[10,20]}$

General instrumentation: ${ }^{1} \mathrm{H}$ NMR spectra were recorded on a Bruker Avance $500 \mathrm{MHz}$ spectrometer. Chemical shifts are reported in parts per million relative to residual solvent peaks. Electrospray ionization mass spectra (ESI-MS) were obtained using a Thermo Finnigan MAT ESI-MS system in negative ion mode. High-resolution mass spectrometry was performed using a Bruker micrOTOFQ II spectrometer in the negative ion mode. Elemental analyses (carbon, hydrogen and nitrogen) were performed with a PerkinElmer 2400 series II analyzer. UV/Vis readings for the enzyme assays were obtained on a BioTek Synergy $\mathrm{H} 1$ hybrid microplate reader. Pt levels were determined on a PerkinElmer Optima ICPOES spectrometer by CMMAC, NUS. The purity of $\mathrm{Pt}^{\mathrm{IV}}$ compounds were determined using analytical HPLC on a Shimadzu Prominence HPLC system, with a Shimpack VP-ODS $C_{18}(5 \mu \mathrm{M}, 120 \AA, 150 \mathrm{~mm} \times$ $4.60 \mathrm{~mm}$ i.d.) column at room temperature at a flow rate of

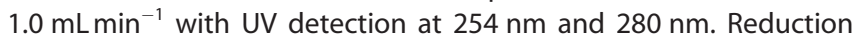
studies were carried out on the same system with modified conditions (described below).

Synthesis of 1: The following procedure was adapted from a literature method. ${ }^{[10]}$ EA (501 mg, $\left.1.65 \mathrm{mmol}\right)$ was dissolved in an excess of oxalyl chloride $(\sim 2.5 \mathrm{~mL})$, and the mixture was heated at reflux under nitrogen at $70^{\circ} \mathrm{C}$ for $1 \mathrm{~h}$, by which time EA had completely dissolved and all effervescence had ceased. The excess oxalyl chloride was removed by vacuum distillation at room temperature, and the mixture was washed with THF $(2 \times 5 \mathrm{~mL})$. The product, a lightyellow liquid, was dried under vacuum. The product was dissolved in acetone $(10 \mathrm{~mL})$ and oxoplatin $(102 \mathrm{mg}, 0.31 \mathrm{mmol}, 0.2$ equiv) was added. The resulting mixture was heated at reflux with stirring at $70^{\circ} \mathrm{C}$ until the solid oxoplatin had completely dissolved and a clear yellow solution was obtained $(\sim 15-30 \mathrm{~min})$. Water $(50 \mathrm{~mL})$ was added immediately to quench the reaction and the reaction mixture was kept at $4^{\circ} \mathrm{C}$ for $12 \mathrm{~h}$, during which a white solid was formed. The liquid phase was decanted, and the residual white solid was washed with diethyl ether $(2 \times 10 \mathrm{~mL})$. The product was purified twice by dissolution in THF $(5 \mathrm{~mL})$ and precipitation using hexane $(\sim 30 \mathrm{~mL})$, then dried in vacuo $(154 \mathrm{mg}, 55 \%$, see SI for characterization data).

Synthesis of EA-NHS: EA (607 mg, $2 \mathrm{mmol}$ ) and NHS (253 mg, $2.2 \mathrm{mmol}, 1.1$ equiv) were dissolved in dry THF $(10 \mathrm{~mL}) . N_{,} N^{\prime}$-Dicyclohexylcarbodiimide ( $454 \mathrm{mg}, 2.2 \mathrm{mmol}, 1.1$ equiv) was separately dissolved in dry THF $(5 \mathrm{~mL})$ and added dropwise to the EA/NHS solution. The mixture was stirred at room temperature for $6 \mathrm{~h}$, during which a white precipitate of dicyclohexylurea (DCU) formed. The white precipitate was removed by filtration and the filtrate was dried under vacuum to afford a white solid that was re-dissolved in $\mathrm{CH}_{2} \mathrm{Cl}_{2}(50 \mathrm{~mL})$. The solution was kept at $4{ }^{\circ} \mathrm{C}$ for $12 \mathrm{~h}$ and then filtered again to remove any additional DCU that had precipitated out. The filtrate was washed with saturated $\mathrm{NaHCO}_{3}$ solution $(40 \mathrm{~mL})$, followed by water $(40 \mathrm{~mL})$, and dried with $\mathrm{Na}_{2} \mathrm{SO}_{4}$. The white solid obtained after evaporation of the filtrate was dried in vacuo (681 $\mathrm{mg}, 85 \%)$.

Synthesis of 2: EA-NHS (72 mg, $0.18 \mathrm{mmol})$ and oxoplatin $(65 \mathrm{mg}$, $0.2 \mathrm{mmol}, 1.1$ equiv) were added to DMSO $(5 \mathrm{~mL})$ and the mixture was stirred at $50^{\circ} \mathrm{C}$ for $12 \mathrm{~h}$. The undissolved oxoplatin was removed by filtration and the filtrate was lyophilized. The residue was dissolved in DMF $(1 \mathrm{~mL})$ and precipitated by addition of dieth$\mathrm{yl}$ ether $(30 \mathrm{~mL})$. The solid was isolated by centrifugation and washed with cold acetone $(5 \mathrm{~mL})$, cold THF $(5 \mathrm{~mL})$, and diethyl 
ether $(2 \times 10 \mathrm{~mL})$ before the product was dried in vacuo $(66.9 \mathrm{mg}$, $60 \%$, see SI for characterization data).

Purification of the $\mathrm{Pt}^{\mathrm{IV}}$ complexes ( 1 and 2 ) by preparative HPLC: Complexes 1 and 2 were obtained with a purity $>99 \%$ using preparatory RP-HPLC from solutions of the respective complexes in DMSO. The conditions used are as follows: YMC Pack-Pro $\mathrm{C}_{18}$ semi-preparative column $(250 \mathrm{~mm} \times 10 \mathrm{~mm}$ i.d.), water-acetonitrile solvent system (total flow $=2 \mathrm{~mL} \mathrm{~min}^{-1}$ ) with gradient elution ( $20 \%$ to $80 \%$ acetonitrile in $20 \mathrm{~min}$, then maintained at $90 \%$ acetonitrile for $10 \mathrm{~min}$, and immediately lowered back to $20 \%$ acetonitrile, and run for a further $15 \mathrm{~min}$ ), UV-vis detection at 254 and $280 \mathrm{~nm}$. The fraction containing the desired compound was collected for each run. The individual fractions were combined, and the solvents were removed by lyophilization to afford the pure $\mathrm{Pt}^{\mathrm{IV}}$ complexes.

GST optimization: GST (1 mg) was dissolved in ultrapure water $(1 \mathrm{~mL})$ to give a stock solution with a working concentration of $1 \mu \mathrm{g} \mu \mathrm{L}^{-1}$. GST solutions of different working concentrations were made from this stock solution by varying the volumes of water and stock solution used. Aliquots of each GST sample solution $(20 \mu \mathrm{L})$ were placed in triplicate wells of a clear $96-$ well plate, along with a column of wells consisting of only ultrapure water $(20 \mu \mathrm{L})$ for the background reading. The master mix was made using ultrapure water $(5400 \mu \mathrm{L})$, phosphate buffer $(900 \mu \mathrm{L}, 1 \mathrm{M}, \mathrm{pH} 6.5)$, and freshly prepared solutions of GSH $(900 \mu \mathrm{L}, 100 \mathrm{~mm}$ in ultrapure water) and CDNB ( $900 \mu \mathrm{L}, 100 \mathrm{~mm}$ in EtOH). Using a multichannel pipette, the master mix $(180 \mu \mathrm{L})$ was introduced into each of the previously loaded wells. After the addition was completed, UV absorbances $(340 \mathrm{~nm})$ were monitored using the kinetics setting on the Gen5 program ( $18 \mathrm{~s}$ scan interval, 6 min total time). The gradient of the linear region (initial $180 \mathrm{~s}$, corrected for background absorption) was obtained, and the average value of the three replicates for each concentration of GST was taken to be the initial rate of the reaction.

GST inhibition assay: Stock solutions of $1(6.15 \mathrm{~mm}), 2(18.61 \mathrm{~mm})$, and EA $(10 \mathrm{~mm})$ were prepared by dissolving the respective compounds in DMSO. The CDDP stock solution $(3.08 \mathrm{~mm}$ ) was made by dissolving solid CDDP in aqueous $\mathrm{NaCl}$ solution $(100 \mathrm{~mm})$. The concentrations of Pt-containing solutions were independently verified using ICP-OES. Sample solutions of varying concentrations were made for each compound by serial dilution of the stock solution using ultrapure water (four-fold dilution, 6 cycles of serial dilution). For each compound, aliquots of solution at each different concentration $(65 \mu \mathrm{L})$ were added to separate aliquots of GST stock solution $(5 \mu \mathrm{L})$, and the mixtures were incubated at room temperature with gentle shaking for $30 \mathrm{~min}$. Ultrapure water was used as the control. The master mix was prepared as previously described. After incubation, aliquots of each sample solution of a particular compound $(20 \mu \mathrm{L})$ were loaded into triplicate wells of a clear $96-$ well plate (seven inhibitor concentrations and one control $\times 3$ replicates and one blank with no enzyme). Using a multichannel pipette, the master mix $(180 \mu \mathrm{L})$ was introduced into each of the wells, and the UV absorbances ( $340 \mathrm{~nm}$ ) of those wells were immediately tracked using the kinetics setting on the Gen5 program (18 s scan interval, $6 \mathrm{~min}$ total time). The average gradient of the linear region of the UV absorbance graph (initial $180 \mathrm{~s}$, corrected for background absorption) was obtained for each concentration of inhibitor, and taken to be the initial rate of the reaction at that specific inhibitor concentration; $50 \%$ inhibitory concentrations $\left(\mathrm{IC}_{50}\right)$ were calculated from concentration-effect curves by interpolation. Evaluation was based on means from at least three inde- pendent experiments, each comprising three replicates per concentration level.

Enzyme kinetics assay: For each compound assessed, GST stock solution $(40 \mu \mathrm{L})$ and the required volume of the corresponding stock solution were added to ultrapure water $(600 \mu \mathrm{L}$ final volume). The solutions were incubated at room temperature with gentle shaking for $30 \mathrm{~min}$. Two sets of master mix were prepared; one with CDNB added, and one without CDNB (the same volume of EtOH was used instead). These two master mixes were mixed in different proportions to obtain solutions of varying CDNB concentrations (see SI). After incubation, aliquots of the GST-inhibitor solution $(20 \mu \mathrm{L})$ were loaded onto a 96-well microplate (eight CDNB concentrations $\times 3$ replicates and one blank). Aliquots of each CDNB mix $(200 \mu \mathrm{L} \times 4)$ were also separately loaded into wells of a second microplate for expedient and simultaneous transfer. Using a multichannel pipette, the various mixes $(180 \mu \mathrm{L})$ were introduced into a corresponding well of GST solution, and the UV absorbances $(340 \mathrm{~nm})$ of those wells were immediately tracked using the kinetics setting on the Gen5 program ( $18 \mathrm{~s}$ scan interval, 6 min total time). The average gradient of the linear region (initial $180 \mathrm{~s}$, corrected for background absorption) was obtained for each CDNB concentration, and taken to be the initial rate of the reaction at that specific concentration of CDNB. The Lineweaver-Burk plot of $1 / V$ against $1 /[C D N B]$ was then plotted for the various inhibitors at different concentrations.

Reduction study of 1: A stock solution of $1(0.154 \mathrm{~mm})$ in DMSO was made and its concentration was determined accurately by ICPOES. Separately, a solution of sodium L-ascorbate $(30 \mathrm{~mm})$ in phosphate buffer ( $200 \mathrm{~mm}, \mathrm{pH} 7.4)$ was made. The stock solution of 1 $(120 \mu \mathrm{L})$, THF $(200 \mu \mathrm{L})$, and phosphate buffer $(1480 \mu \mathrm{L}, 200 \mathrm{~mm}$, $\mathrm{pH}$ 7.4) were mixed in a HPLC vial and the reduction was initiated by adding the sodium L-ascorbate solution $(200 \mu \mathrm{L})$ into the vial, capping it, and shaking vigorously for $5 \mathrm{~s}$. The vial was then placed in the HPLC autosampler, and the batch run was initiated. Injections $(50 \mu \mathrm{L})$ were performed at 20-min intervals, and detection was by UV ( 214 and $254 \mathrm{~nm}$ ). The area of the starting material peak was monitored over time. A Shimpack VP-ODS $C_{18}$ analytical column $(5 \mu \mathrm{M}, 120 \AA, 150 \mathrm{~mm} \times 4.60 \mathrm{~mm}$ i.d.) was used, with an iso-

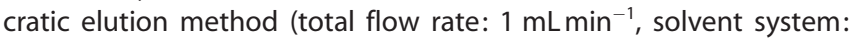
$60 \%$ acetonitrile and $40 \%$ water).

Reduction study of 2: A stock solution of $2(0.205 \mathrm{~mm})$ in phosphate buffer ( $200 \mathrm{~mm}, \mathrm{pH}$ 7.4) was made and its concentration was determined accurately by ICP-OES. Separately, a solution of sodium L-ascorbate $(0.3 \mathrm{~mm})$ in phosphate buffer $(200 \mathrm{~mm}, \mathrm{pH} 7.4)$ was made. The stock solution of $2(100 \mu \mathrm{L})$ and phosphate buffer $(1800 \mu \mathrm{L}, 200 \mathrm{~mm}, \mathrm{pH}$ 7.4) were mixed in a HPLC vial. The reduction was started by adding the sodium L-ascorbate solution $(100 \mu \mathrm{L})$ into the vial, capping it, and shaking vigorously for $5 \mathrm{~s}$. The vial was then placed in the HPLC autosampler, and the batch run was initiated. Injections $(50 \mu \mathrm{L})$ were performed at $10 \mathrm{~min}$ intervals, and detection was by UV (214 and $254 \mathrm{~nm})$. The area of the starting material peak was monitored over time. A Shimpack VP-ODS $C_{18}$ analytical column $(5 \mu \mathrm{M}, 120 \AA, 150 \mathrm{~mm} \times 4.60 \mathrm{~mm}$ i.d.) was used, with an isocratic elution method (total flow= $1 \mathrm{~mL} \mathrm{~min}{ }^{-1}$, solvent system $=40 \%$ acetonitrile and $60 \%$ water).

MTT assay: The cytotoxicity of the compounds was determined by a colorimetric microculture 3-(4,5-dimethylthiazol-2-yl)-2,5-diphenyltetrazolium bromide (MTT) assay. The cells were harvested from culture flasks by trypsinization and seeded into Cellstar 96-well microculture plates (seeding density: 6000 cells per well). After the cells had resumed exponential growth for $24 \mathrm{~h}$, they were exposed 
to the compounds under investigation at different concentrations in media for $72 \mathrm{~h}$. The compounds (1, 2, CDDP, and EA) were diluted separately in complete medium to the desired concentrations, and this solution $(100 \mu \mathrm{L})$ was added to each well and serially diluted to other wells. After exposure for $72 \mathrm{~h}$, compound solutions were replaced with MTT in media $\left(100 \mu \mathrm{L}, 5 \mathrm{mg} \mathrm{mL}^{-1}\right)$ and incubated for an additional $45 \mathrm{~min}$. Subsequently, the medium was aspirated and the purple formazan crystals formed in viable cells were dissolved in DMSO (100 $\mu \mathrm{L}$ per well). Optical densities $(570 \mathrm{~nm})$ were measured with a microplate reader. The quantity of viable cells was expressed in terms of treated/control (T/C) values by comparison with untreated control cells, and $50 \%$ inhibitory concentrations $\left(\mathrm{IC}_{50}\right)$ were calculated from concentration-effect curves by interpolation. Evaluation was based on means from at least three independent experiments, each comprising six replicates per concentration level.

Determination of residual GST levels in treated A2780 cells: The protocol was adapted from a literature protocol. Human ovarian carcinoma A2780 cells were seeded into 6-well plates (seeding density: $10^{6}$ cells per well, $2 \mathrm{~mL}$ ). After the cells were allowed to resume exponential growth for $24 \mathrm{~h}$, they were washed once with sterile PBS, replaced with fresh growth medium and exposed to the compounds $(\mathbf{1}, \mathbf{2}, E A$, and $C D D P)$ separately at the required concentrations for $1.5 \mathrm{~h}$, then washed with sterile PBS $(2 \times 1 \mathrm{~mL})$. After adding PBS $(300 \mu \mathrm{L})$ to each well, cells were harvested using cell scrapers, transferred into separate $1.5 \mathrm{~mL}$ microtubes and centrifuged $(250 \times g)$ for $7 \mathrm{~min}$. After removing the supernatant, the cell pellets were re-dissolved in Protease Inhibitor Cocktail $(70 \mu \mathrm{L}$, in sterile PBS). The cells were disrupted by five cycles of freezing and thawing, and centrifuged (13000 rpm) for $15 \mathrm{~min}$ to separate the cell pellet. The supernatant $(20 \mu \mathrm{L})$ was added to triplicate wells of a 96-well microplate. The master mix was made as per the GST inhibition assay, and the GST inhibition assay was carried out as previously described.

The chorioallantoic membrane model (CAM): A2780 human ovarian carcinoma cells (ECACC, Salisbury, UK) were maintained in RPMI-1640 cell culture medium supplemented with GlutaMAX'M (Gibco, Carlsbad, CA, USA), 10\% bovine calf serum (Sigma-Aldrich, St. Louis, MO, USA) and $1 \%$ antibiotics (pen/strep, Sigma-Aldrich). Fertilized chicken eggs were incubated in a hatching incubator (relative humidity $65 \%, 37^{\circ} \mathrm{C}$ ) for seven days, as previously described. On egg development day $7,10^{6}$ A2780 cells were transplanted on the surface of the chorioallantoic membrane (CAM) as a $25 \mu \mathrm{L}$ hanging drop. Vascularized tumors appeared approximately three days after inoculation on the surface of the CAM. Compound $\mathbf{2}$ or CDDP were administered intravenously on treatment days 1 and 2, after which tumor size and toxicity was monitored daily over a period of eight days. Tumors were measured daily: volume $=$ (largest diameter $)^{2} \times($ perpendicular diameter $) \times 0.5$.

Statistical analysis: Statistical analysis was performed based on a two-way ANOVA with post-hoc Dunnett's multiple comparisons test performed in GraphPad Prism.

\section{Acknowledgements}

This study was supported by the European Union (ERC-2015-StGLS7-680209) to P.N.-S., a Ministry of Education (Singapore) research grant (R143-000-680-114) to W.H.A., and a National University of Singapore Research Scholarship to K.G.Z.L.

\section{Conflict of interest}

The authors declare no conflict of interest.

Keywords: cancer - cytotoxicity - medicinal chemistry platinum $\cdot$ redox chemistry

[1] S. Dasari, P. B. Tchounwou, Eur. J. Pharmacol. 2014, 740, 364-378.

[2] a) T. Hu, Z. Li, C.-Y. Gao, C. H. Cho, World J. Gastroenterol. 2016, 22 6876-6889; b) R. J. Parker, A. Eastman, F. Bostick-Bruton, E. Reed, J. Clin. Invest. 1991, 87, 772-777.

[3] L. Galluzzi, L. Senovilla, I. Vitale, J. Michels, I. Martins, O. Kepp, M. Castedo, G. Kroemer, Oncogene 2012, 31, 1869-1883.

[4] S. Jiang, A. W. Pan, T. - y. Lin, H. Zhang, M. Malfatti, K. Turteltaub, P. T. Henderson, C.-x. Pan, Chem. Res. Toxicol. 2015, 28, 2250-2252.

[5] J. W. Critchfield, C. J. Welsh, J. M. Phang, G. C. Yeh, Biochem. Pharmacol. 1994, 48, 1437-1445.

[6] a) D. Sheehan, G. Meade, V. M. Foley, C. A. Dowd, Biochem. J. 2001, 360, $1-16$; b) C. Peklak-Scott, P. K. Smitherman, A. J. Townsend, C. S. Morrow Mol. Cancer Ther. 2008, 7, 3247-3255.

[7] E. W. LaPensee, S. J. Schwemberger, C. R. LaPensee, E. M. Bahassi, S. E. Afton, N. Ben-Jonathan, Carcinogenesis 2009, 30, 1298-1304.

[8] a) K. D. Tew, A. M. Bomber, S. J. Hoffman, Cancer Res. 1988, 48, 3622 3625 ; b) J. Hansson, K. Berhane, V. M. Castro, U. Jungnelius, B. Mannervik, U. Ringborg, Cancer Res. 1991, 51, 94-98; c) T. Rhodes, P. R. Twentyman, Br. J. Cancer 1992, 65, 684-690.

[9] a) C. F. Chin, S. Q. Yap, J. Li, G. Pastorin, W. H. Ang, Chem. Sci. 2014, 5, 2265-2270; b) E. Petruzzella, J. P. Braude, J. R. Aldrich-Wright, V. Gandin, D. Gibson, Angew. Chem. Int. Ed. 2017, 56, 11539-11544; Angew. Chem. 2017, 129, 11697-11702; c) T. C. Johnstone, K. Suntharalingam, S. J. Lippard, Chem. Rev. 2016, 116, 3436-3486.

[10] a) W. H. Ang, I. Khalaila, C. S. Allardyce, L. Juillerat-Jeanneret, P. J. Dyson, J. Am. Chem. Soc. 2005, 127, $1382-1383$; b) I. Zanellato, I. Bonarrigo, M. Sardi, M. Alessio, E. Gabano, M. Ravera, D. Osella, ChemMedChem 2011, 6, 2287-2293; c) S. Li, C. Li, S. Jin, J. Liu, X. Xue, A. S. Eltahan, J. Sun, J. Tan, J. Dong, X. J. Liang, Biomaterials 2017, 144, 119-129.

[11] a) J. Yang, X. Sun, W. Mao, M. Sui, J. Tang, Y. Shen, Mol. Pharm. 2012, 9, 2793-2800; b) M. R. Reithofer, S. M. Valiahdi, M. Galanski, M. A. Jakupec, V. B. Arion, B. K. Keppler, Chem. Biodiversity 2008, 5, 2160-2170 c) D. Y. Q. Wong, C. H. F. Yeo, W. H. Ang, Angew. Chem. Int. Ed. 2014, 53, 6752-6756; Angew. Chem. 2014, 126, 6870-6874; d) A. Massaguer, A. Gonzalez-Canto, E. Escribano, S. Barrabes, G. Artigas, V. Moreno, V. Marchan, Dalton Trans. 2015, 44, 202-212; e) H. Xiao, L. Yan, Y. Zhang R. Qi, W. Li, R. Wang, S. Liu, Y. Huang, Y. Li, X. Jing, Chem. Commun. 2012, 48, 10730-10732; f) Y. Sun, T. Shi, L. Zhou, Y. Zhou, B. Sun, X. Liu, J. Microencapsulation 2017, 34,675-686; g) H. Xiao, G. T. Noble, J. F. Stefanick, R. Qi, T. Kiziltepe, X. Jing, B. Bilgicer, J. Controlled Release 2014, 173, 11-17; h) P. A. Ma, H. Xiao, X. Li, C. Li, Y. Dai, Z. Cheng, X. Jing, J. Lin, Adv. Mater. 2013, 25, 4898-4905; i) J. Li, Z. Lyv, Y. Li, H. Liu, J. Wang, W. Zhan, H. Chen, H. Chen, X. Li, Biomaterials 2015, 51, 12-21; j) Q. Cheng, Y. Liu, Wiley Interdiscip. Rev. Nanomed. Nanobiotechnol. 2017, 9, e1410.

[12] L. J. Parker, L. C. Italiano, C. J. Morton, N. C. Hancock, D. B. Ascher, J. B. Aitken, H. H. Harris, P. Campomanes, U. Rothlisberger, A. De Luca, M. Lo Bello, W. H. Ang, P. J. Dyson, M. W. Parker, Chem. Eur. J. 2011, 17, $7806-$ 7816.

[13] S. Q. Yap, C. F. Chin, A. H. Hong Thng, Y. Y. Pang, H. K. Ho, W. H. Ang, ChemMedChem 2017, 12, 300-311.

[14] W. H. Habig, M. J. Pabst, W. B. Jakoby, J. Biol. Chem. 1974, 249, $7130-$ 7139

[15] H. Lineweaver, D. Burk, J. Am. Chem. Soc. 1934, 56, 658-666.

[16] a) H. J. Atkinson, P. C. Babbitt, Biochemistry 2009, 48, 11108-11116; b) A. Oakley, Drug Metab. Rev. 2011, 43, 138-151.

[17] S. Awasthi, S. K. Srivastava, F. Ahmad, H. Ahmad, G. A. S. Ansari, Biochim. Biophys. Acta Protein Struct. Mol. Enzymol. 1993, 1164, 173-178.

[18] a) G. Agonigi, T. Riedel, S. Zacchini, E. Păunescu, G. Pampaloni, N. Bartalucci, P. J. Dyson, F. Marchetti, Inorg. Chem. 2015, 54, 6504-6512; b) G. Agonigi, T. Riedel, M. P. Gay, L. Biancalana, E. Oñate, P. J. Dyson, G. Pam- 
paloni, E. Păunescu, M. A. Esteruelas, F. Marchetti, Organometallics 2016 35, 1046-1056; c) E. Păunescu, M. Soudani, P. Martin, R. Scopelliti, M. Lo Bello, P. J. Dyson, Organometallics 2017, 36, 3313-3321; d) E. Păunescu, M. Soudani, C. M. Clavel, P. J. Dyson, J. Inorg. Biochem. 2017, 175, $198-$ 207.

[19] a) A. Weiss, D. Bonvin, R. H. Berndsen, E. Scherrer, T. J. Wong, P. J. Dyson, A. W. Griffioen, P. Nowak-Sliwinska, Sci. Rep. 2015, 5, 8990; b) P. NowakSliwinska, T. Segura, M. L. Iruela-Arispe, Angiogenesis 2014, 17, 779-804 c) P. Nowak-Sliwinska, A. Weiss, J. R. van Beijnum, T. J. Wong, W. W. Kilarski, G. Szewczyk, H. M. W. Verheul, T. Sarna, H. van den Bergh, A. W. Griffioen, Cell Death Dis. 2015, 6, e1641.
[20] a) V. Y. Kukushkin, Å. Oskarsson, L. I. Elding, N. Farrell, S. Dunham, S. J. Lippard in Inorganic Synthesis, Wiley, 2007, pp. $141-144$; b) J. Z. Zhang, P. Bonnitcha, E. Wexselblatt, A. V. Klein, Y. Najajreh, D. Gibson, T. W. Hambley, Chem. Eur. J. 2013, 19, 1672-1676.

Manuscript received: February 20, 2018

Revised manuscript received: March 27, 2018

Accepted manuscript online: April 10, 2018

Version of record online: May 28, 2018 